\title{
Information Support for Making Standard Management Decision with the Help of Hardware- Software System
}

\author{
Mark Stanislavovich Lioublinskiy \\ Department of Economics and production management \\ Kovrov State Technological Academy \\ Kovrov, Russian Federation \\ lumast@yandex.ru
}

\author{
Ludmila Ivanovna Shemonayeva \\ Department of Electrical engineering \\ Kovrov State Technological Academy \\ Kovrov, Russian Federation
}

\author{
Yevgeny Anatolievich Chashchin \\ Department of Electrical engineering \\ Kovrov State Technological Academy \\ Kovrov, Russian Federation
}

\author{
Vladimir Valerievich Kotov \\ Department of Applied Mathematics and Computer-Aided \\ Design Systems \\ Kovrov State Technological Academy \\ Kovrov, Russian Federation
}

\begin{abstract}
Raising the production efficiency of high-tech enterprises can be achieved through the introduction of an information support system for making standard management decisions on the basis of machine loading analysis. The aim of the article is to offer, on the basis of analyzing the problems revealed during large-scale introduction of NC-machines, a target model of information support system for decision-making in accordance with the long-range architecture of enterprise management and production management. The hardware-software system presented allows one to collect information on the machine loading (payload work, idling mode, downtime etc.) automatically, avoiding any influence of the "human factor", as well as to generate the report and the machine assignment for each piece of equipment in the chosen time period. The technical decisions used in creating the hardware-software system are based on the integrated study of physical and engineering processes of torsion torque control on the actuators measuring small alterations of current by means of bush-type support transformers, as well as on the development of software components with open source code. The software part of the system has been realized on the Node.js. platform. The developed information system of management decision-making at an enterprise is sure to considerably increase the labor productivity of its personnel.
\end{abstract}

Keywords - Information system, management decisions, labor productivity

\section{INTRODUCTION}

The large-scale introduction of NC-machines at the Kovrov enterprises has brought to light plenty of problems. One of them is connected with the lack of qualified personnel capable of solving efficiently the organizational and engineering problems in new conditions. It became apparent due to the scarcity of operators, setup specialists for NCmachines, technological engineers, first-line production managers etc.

The operative decision of the problem was found in the establishment of the regional Center of personnel training on the basis of JSC "KEMP" which has begun training manpower for the enterprises of Kovrov and Vladimir region in the framework of its network cooperation with the Kovrov State Technological Academy named after V.A. Degtyarev, MSTU "Stankin", Vladimir State University named after A.G. and N.G. Stoletovs, industrial and liberal arts college №35. However, the majority of the humanpower at the enterprises in the region today still belongs to mature age groups, and is used to dealing with outdated general-purpose equipment, with piece-work payment and the extensive method of work management. Moreover, first-line production managers appeared to be both professionally and morally unprepared to organize production based on the new-generation equipment, to manage young qualified workers, often having a higher education, to superintend in the conditions of time-rate payment. Higher requirements for the terms and the quality of the output, necessity of raising the efficiency of production processes and the transition of enterprises to the principles of "frugal production" have made even more noticeable the lack of organizational and engineering competences in the work of first-line production managers. The above-mentioned problems did not permit to get a full effect from NC-machines application, though it is traditionally believed that the usage of such machines results in:

- raising the efficiency due to the lower number of operations and setting blocks; 
- getting better and more stable quality parameters (especially form deviations and geometric relationships);

- reducing the period of product cycle owing to the "builtin" time, to shortening the inter-operational periods etc. [2, 3]

However, the analysis NC-machines application at Kovrov's enterprises has shown that the hopes of their chief executives for a considerable rise in production efficiency as a result of large-scale introduction of NC-machines have not been justified (table 1).

Table I. Problems revealed in the large-scale introduction of NC-machines

\begin{tabular}{|l|l|}
\hline \multicolumn{1}{|c|}{ Plant executive's desire } & \multicolumn{1}{|c|}{ Actual state of things } \\
\hline Expansion of the output program & $\begin{array}{l}\text { Failure to fulfill the already } \\
\text { existing plan }\end{array}$ \\
\hline A 100\% machine utilization & Equipment downtime \\
\hline Quick readjustment & Prolonged readjustments \\
\hline $\begin{array}{l}\text { Maximum utilization of production } \\
\text { resource }\end{array}$ & Delay \\
\hline Availability of qualified personnel & Low level of proficiency \\
\hline Low reject limit & High reject limit \\
\hline Low repair and maintenance bills & $\begin{array}{l}\text { High repair and maintenance } \\
\text { bills }\end{array}$ \\
\hline $\begin{array}{l}\text { Reduction of costs of tools and } \\
\text { appliances }\end{array}$ & $\begin{array}{l}\text { Increasing costs of tools and } \\
\text { appliances }\end{array}$ \\
\hline $\begin{array}{l}\text { Automatic control of equipment } \\
\text { operation }\end{array}$ & $\begin{array}{l}\text { Influence of the "human } \\
\text { factor" on the output data }\end{array}$ \\
\hline
\end{tabular}

Low quality of production managers training underlies most of the reasons of insufficient effect from high-tech equipment application. Inadequate knowledge has become evident in the spheres of modern organizational technologies of production management, of outfit and equipment, software etc. Apart from that, making correct management decisions is hindered by the absence of reliable data on the actual usage of production resource (period of NC-machines effective work). $[1,11,12]$

The analysis has revealed a few more factors influencing production managers and resulting in lower efficiency:

- organizational;

- physiological;

- personal.

The physiological factor (especially among mature managers) becomes apparent in the loss of eye-sight and hearing, alcohol addiction, cumulative fatigue (occupational exhaustion), diseases, disability etc.

The personal factor has shown itself in poor selforganization, excessive self-assurance, absent-mindedness, anxiety etc.

The organizational factor is evident in the low level of labor organization and low production standards, social and psychological tension in work collectives, high intensity of work and overload from numerous duties, insufficient quality of management and absence of distinct management standards of work . [14, 15]

The negative influence of the organizational factor can be diminished by re-engineering on the principles of "frugal production" $[7,13]$. That is going to facilitate increasing the efficiency of production managers. For example, introducing the standards of corporate culture allowed managers to monitor the state of the supervised area and personnel on the basis of "check-lists", without taking their own "original" management decisions. It resulted in the improvements in the organization and work place attendance, introduction of mechanization and automation of labor, in raising the quality and improvement of product appearance, in attracting the employees to updating the activity of the production sites on the basis of Kaizen offers. Recommendations to personnel given in the process of monitoring the corporate culture have helped to bring the technological equipment into accord with the anatomic, physiological and psychological requirements, to improve the hygiene and sanitary conditions of work and community services to workers at the enterprise. The general culture standards have risen, which manifested itself in the higher proficiency, competence, attitude to the work fulfilled, behavioral model.

At the same time, the introduction of standards does not exclude the necessity of receiving precise data about the work of production areas free from the influence of the "human factor". To evaluate the utilization of the equipment, for example, it is important to have information on the machine effective work. The machine effective work, in our case, implies the productive time during which surface formation occurs without the operator's participation.

\section{ANALYSIS OF THE CURRENT SYSTEMS OF MONITORING THE EQUIPMENT OPERATION}

At present, there are several ways of monitoring the efficiency of production equipment application. One of the most up-to-date is real-time remote control of machine-tool operation. For example, the Danish company CIMCO Integration offers for industrial enterprises a hardwaresoftware system for manufacturing purposes MDS «Machine Data Collection» (systems of machine-tool monitoring). The version MDC-Max 5 is capable of generating reports from the machine column on the period of work, idling or downtime of the equipment. The information is sent from the machine-tool through the wire network to the server where it is kept and processed centrally. The system is capable of controlling a large base of equipment. Another way of control is the system of adaptive management and monitoring OmativeACM made by OMATIVE Systems company (Israel). The system function implies monitoring the equipment operation by means of realtime vibration sensing. The system allows making statistic evaluation of machine operation efficiency (MOE) for a long period of time and in any chosen time interval, automatically calculating the efficiency characteristics, showing the results in tabular and graphic form. Integration and export of data to Excel tables and data exchange with other factory information systems (planning, quality control etc) have also been made possible. Control is achieved by means of vibration sensors installed on the equipment. Nevertheless, the vibro-diagnostic system seems excessive if used in the metal-working equipment in the suggested way. The next method of evaluating machine-tool operation is the system of monitoring equipment operation Intenta (Siemens). The system makes it 
possible to analyze the equipment performance (NC-machines from Siemens) in automatic mode on the basis of the data received directly from the $\mathrm{NC}$ columns. It also provides for a possibility to generate the users' own reports if desired. The major limitation of the system is its ability to work only with NC-machines from Siemens. [5, 16, 17]

The principal advantage of the above-named systems is practical impossibility of the "human factor" influence on data alteration, as the statistics of the bug-free programs, electric power, time of tool run, etc. are carried out automatically, i.e. without the operator's participation. Their common drawbacks, probably, include:

- absence of direct interaction with some NC-systems and limitations in getting overall data on the machine operation, especially in case of the joint operation of machines from different manufacturers;

- the solutions described are characterized as costly.

In the authors' view, one of the promising ways of evaluating the efficiency of equipment devoid of the abovementioned drawbacks is monitoring the energy consumption of the equipment, offered by F.N. Dorofeev (copyright certificate №44073), who has worked out a device for recording the time of equipment operation under load, in idle mode, and machine downtime. The design is based on recording the power consumption.

During downtime the machine does not consume electricity, in the idling mode consumption of electricity is the lowest, when switching over from idling to working stroke the value of current intensity increases, and the time of the machine effective work is counted. The advantage of the method is in the following:

- no reprogramming or alteration in the machine tooling is needed;

- it becomes possible to carry out the monitoring of both domestically produced and foreign equipment regardless of the year of manufacture;

- the new machine-tools remain under contract guarantee, as there is no direct interference in the work of the equipment.

\section{DESCRIPTION OF BENCH-TOP EQUIPMENT USED FOR THE DEVELOPMENT OF THE HARDWARE-SOFTWARE SYSTEM}

To estimate practical application of the machine monitoring method under consideration, bench testing was carried out, in which the operation modes of the equipment were simulated with the help of a magnetic brake (fig.1) that provided imitation of the machine motor load from idling to the rated load.

Information on the intensity of the current consumed by the actuating induction motor of the A42-4 type with the rated power of 1.5 kilowatt was transmitted through the microcontroller Arduino Uno R3 (fig. 2, MC) to the personal computer (PC), where it was transformed by software into visualized curves of equipment performance. (fig.2)

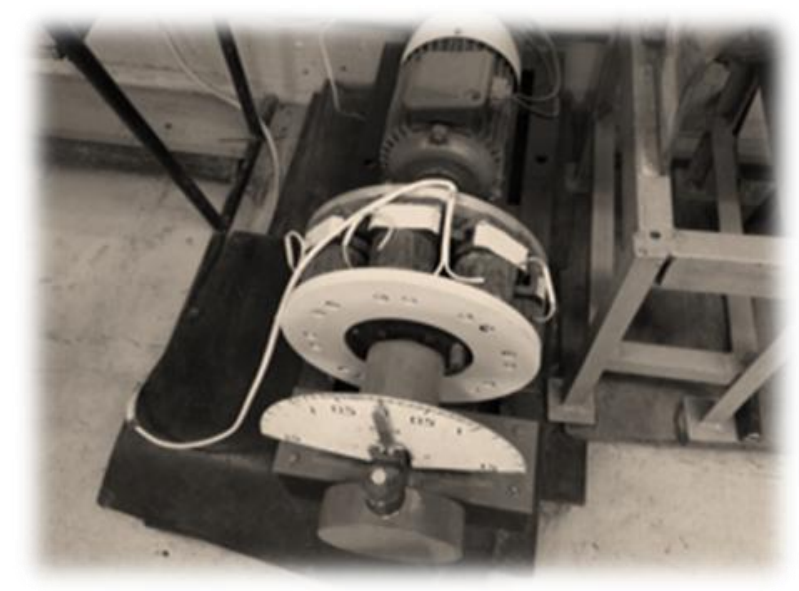

Fig. 1. Experimental test bench

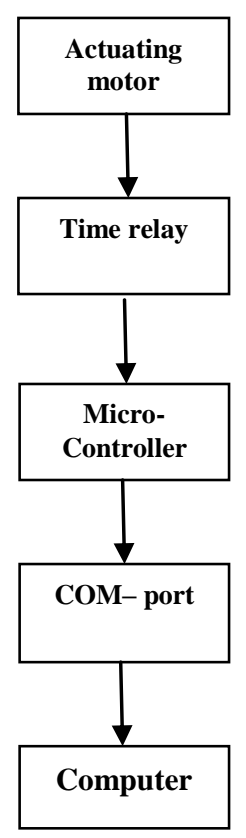

Fig. 2. Algorithm of signal processing in MC

The consumed power intensity varied from $3.4 \mathrm{~A}$, that corresponds to idling, to $4.8 \mathrm{~A}$, when load was imitated by magnetic brake. Information on the magnitude of the current flowing through the motor winding was taken by measuring the voltage drop on the reference bridge of $0.1 \mathrm{ohm}$ built into motor power supply circuit. In starting the motor, a large launching current appears, 5 to 10 times greater than the rated value; that it why in order to avoid microcontroller failure, a time relay is installed between the bridge and the microcontroller, with time delay up to 5 seconds, which sends a signal to the microcontroller inputs after the start-up current drops. The signal coming to the microcontroller input is recomputed into current and sent to the COM-port of the computer which fulfills further graph-analytic processing of information. The algorithm of microcontroller operation is shown in fig. 3 . 


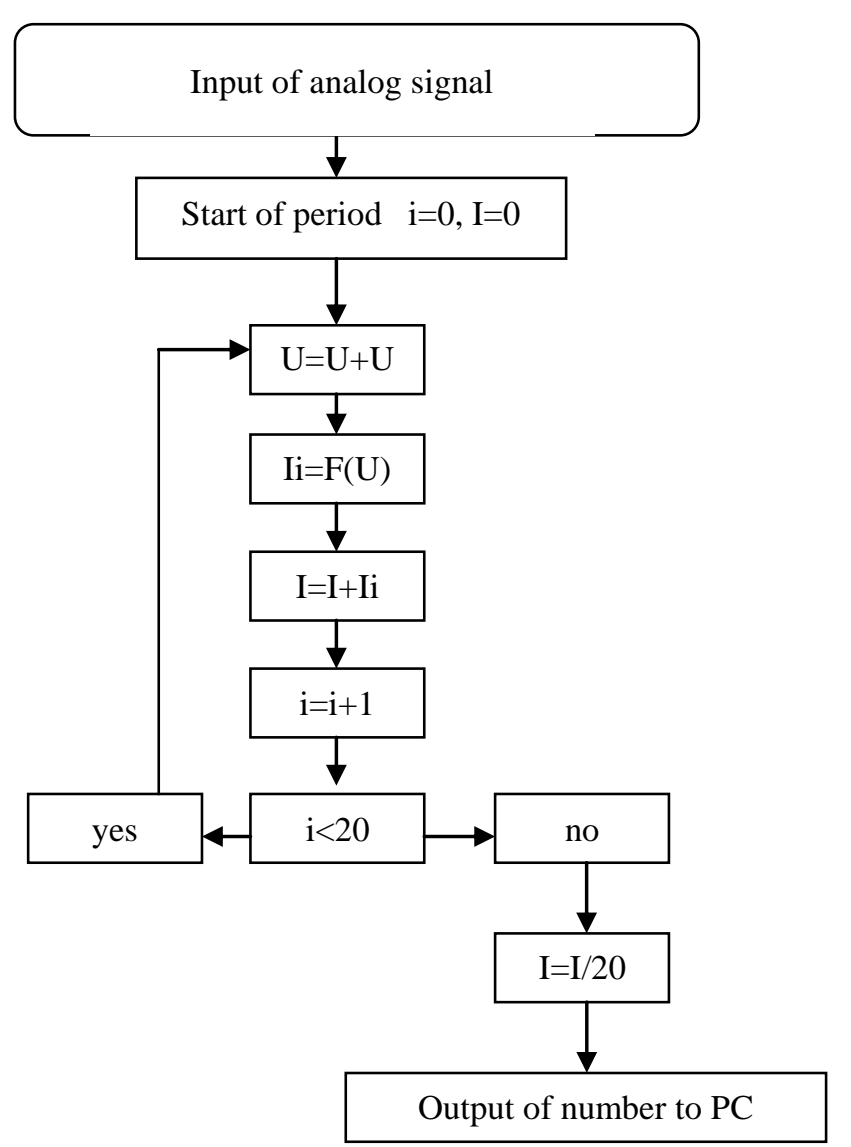

Fig.3. Algorithm of microcontroller performance

The device works in the following way. The output signal has a non-harmonic form because of the digital noise. To suppress the digital noise, a signal sample is made every 0.005 seconds for two periods, and the average value of current intensity $I$ is found and sent to the computer.

\section{DESCRIPTION THE SYSTEM SOFTWARE COMPONENT OPERATION}

The software part of the hardware-software system is implemented on the platform Node.js, which makes possible easy interaction with various input-output means, as well as with the developed microcontroller.

The system collects the real-time information from the controller and sends it to the data base which is accessible for analysis and generation of various reports. The built-in relational database $S Q L i t e$ has been chosen for its good speed characteristics and ability to process large volumes of data. The developed system works under the control of operational systems of the Windows family (XP and higher) or Linux. The minimum system requirements are $250 \mathrm{MB}$ of the disc space for installation, $128 \mathrm{MB}$ of main memory. Access to the system is made through the web-interface. It allows to access to the data from any location in the plant network and through the Internet if required, there is no need to install any special equipment, the only necessary thing being a browser. The system functions in two modes - administrative and userdefined. The former implies possibility of connecting and disconnecting sensors, and regulating their parameters. In the user mode, it is possible to generate reports on the equipment performance. To do that, it is necessary to choose a typical time interval (day, week, month) and manually enter the date and time (fig.4) according to which the report will be made.

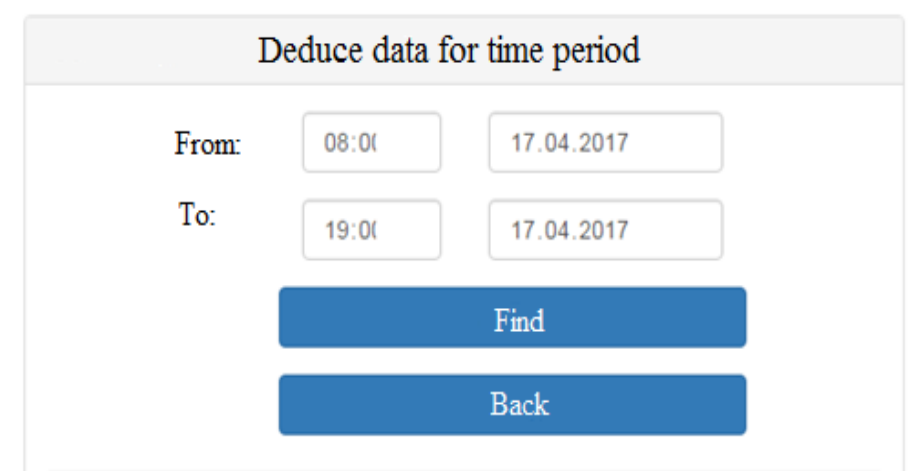

Fig.4. The time selecting form for generating a report

As a result, information on the work cycles and downtime cycles of the equipment will be visually represented (fig 5). The graphs and bar charts use the following color code: redequipment is off (not working), green - idling, blue - load work, grey - no information.
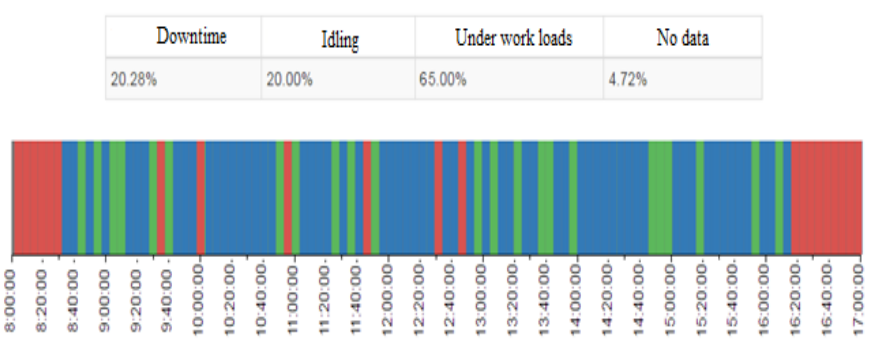

Fig. 5. Graphic representation of report on equipment performance

The next stage of the work was testing the device in a mechanical laboratory. A screw-cutting lathe IZH95TS-1 was used in the role of equipment. The current sensor was installed in the distribution switchboard before the machine-tool, and the information was then sent to the PC which generated the reports in the format developed. Information was taken during idle work and under the load from turning a rod (circle $24 \mathrm{~mm}$, steel 45) on the outer surface. The machining was done by a through-pass single-point cutting tool with hard-alloyed insert T15K6 (fig.6). 


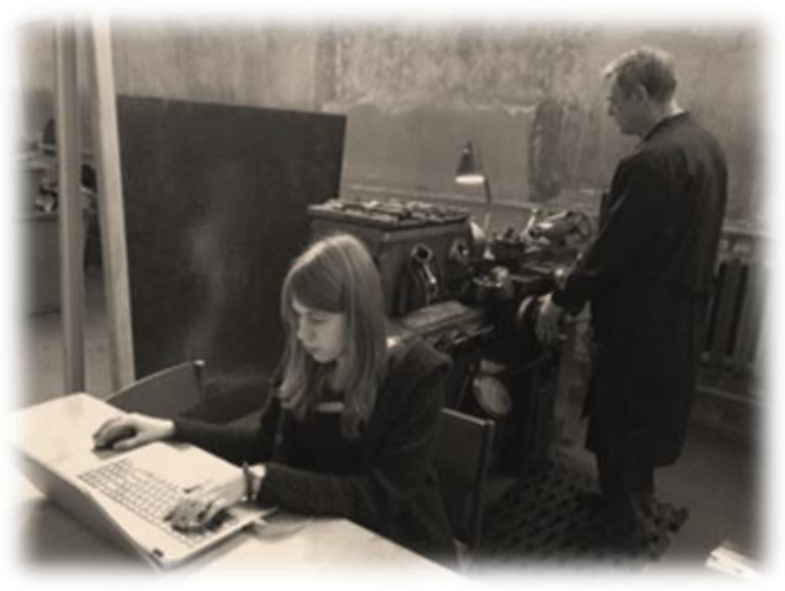

Fig.6. Testing in mechanical laboratory

The laboratory trials have helped to refine and calibrate the controller. Integrating the device in the enterprise management system was the final stage of the work. With this purpose the information from the machine-tools was transferred to the PC in the workshop, and then further on, through the enterprise network to all persons concerned for making management decisions stated in the enterprise standards.

\section{Acknowledgments}

The work is done with the support of the RFFR, project number 17-46-330198

\section{References}

[1] Y.Y. Lavrishcheva, M.S. Lioublinskiy, S.G.Tyutyugina, «Inner innovational environment of an enterprise: factors and mechanisms», monograph, Ufa, «Infinity» Publishing house, 2013, 100 p.

[2] I.L. Volchkevich, «Investigation of actual efficiency of modern highcapacity NC equipment», Mechanical engineering and Technosphere of XXI century, Proceeding of the XVII international scientific and technical conference, Donetsk, 2011, pp. 144-145.

[3] I.L Volchkevich, «Expedient application of NC machine-tools in conditions of multi-product manufacture», Science and education. Electronic engineering edition, No.2, February 2012.

[4] G.D. Volkova, O.V. Novosyolova, «Research of a mechanical plant management system», Moscow, Publishing center "Mechanical engineering technology”, No.3, pp.62-66, 2010.

[5] M. Gushchin, L. Kuznetsova et al., «Elements of a common information space in automatic production», Intelligent production No.1,Vol.29, pp.40-42, 2015.

[6] N.S. Davydova, Y.P. Klochkov, «Model of management in introducing the system of "frugal production" at an enterprise», Proceedings of the Udmurt University, No.2, Vol.4, pp. 32-35, 2012.

[7] N.S Davydova, «Frugal production as a factor of raising an enterprise competitiveness», Engineering bulletin of the Don region, No.2, pp. 720-727, 2012.

[8] A.D. Zaretsky, T.Y. Ivanova, «Innovational application of technologies as the basis for frugal production», Fundamentals of economics, management and law, No.3, pp. 59-62, 2012.

[9] Y.P. Klochkov, «"Frugal production”: concepts, principles, mechanisms», Engineering bulletin of the Don region, No.2, pp. 429 437, 2012.
[10] N.P. Badalyan, Y.A Chashchin, «Making a mathematical model of permissible steady-state regime for an electric power plant», Bulletin of ISEU, No.3, pp. 43-4, 20127.

[11] M.S. Lioublinskiy, «Resources for raising the inner efficiency of enterprises», The world of scientific discoveries, Krasnoyarsk: Research and innovation center, No.11.9, Vol.47, pp. 251-255, 2013.

[12] M.S. Lioublinskiy, «Technique for revealing losses in a manufacturing system: teaching aid», Kovrov, FSBEI HPE "KSTA named after V.A. Degtyarev", 2015, 50p.

[13] M.S. Lioublinskiy, «Use of instruments of Lean production for improvement of quality of products», Scientific almanac (Economic sciences), 2016, No.4-1,Vol.18, pp.131-135, 2016.

[14] P.V. Terelyansky, «Experience in decision-making. Design experience: monograph», Systems of decision-making support, Volgograd STU, Volgograd, 2009, 127p.

[15] J. N. Cleveland, L.M. Shore, «Self- and supervisory perspectives on age and work attitudes and performance», Journal of Applied Psychology, pp. 469-484, 1992.

[16] R.C. Hansen, «Overall Equipment Effectiveness: a powerful production maintenance tool for increased profits», Industrial Press, 2001. ISBN 08311-3138-1

[17] R.C. Hansen, «Unleashing the Power of OEE, Maintenance technology articles», 1998

[18] D.N.Aksenov, K.I. Kurganov, E.A.Chashchin «Hardware and software of dispatching of the enterprise Karyeroupravleniye», Online magazine "NAUKOVEDENIYE" Vol.9, No.3, 2017.

[19] R.S.Golov,A.P.Agarkov, A.V.Rozhdestvenskiy, «Control systems innovative investment activities of the industrial organizations and preparation of machine-building production», Moskow, Dashkov and Co, 2014, 448 p.

[20] S. Bagui, R. Earp, «Database Design Using Entity-Relationship Diagrams», (Foundations of Database Design), New York, Auerbach Publications, 2015, $371 \mathrm{p}$.

[21] E.R. Panteleev, «Methods of sorting and search», Manual, Ivanovo: Prod.in IGEU, 2006, 80 p. 